\title{
Figures and Musical Examples
}

\section{Figures}

1. Comparison of music and language

2. List of traits for two philosophical temperaments, based on William James, Pragmatism (1907)

3. Seeger's fourteen principles of music criticism

4. Process of musical judgment, Tradition and Experiment in the New Music

5. Three essential principles of Seeger's theory of music criticism 83

6. Matrix comparing inflections with musical functions

7. Quality of vertical intervals arranged in order of increasing dissonance

8. Analogues of "consonance" and "dissonance" for the nonpitch functions

9. Examples of "consonant" proportions: (a) and (b); and "dissonant" proportions: (c) and (d)

10. Ruth Crawford, String Quartet: III, mm. 39-58: Patterns of rhythm and instrumental ordering created by succession of climaxes ( $1=$ cello; $2=$ viola; $3=$ violin II; and $4=$ violin I)

11. Chart of neumes and neume-analogues ("acc" = accelerando; "rall" = rallentando)

12. Seeger's form-neume analysis of Richard Wagner's Tristan und Isolde, act $3, \mathrm{~mm} . \mathbf{1 - 5 3}$

13. Comparison of Combarieu's theory of poetic meter (based on Aristoxenus) and Seeger's theory of melody 
14. Guido Adler's conspectus of Musikwissenschaft, "Umfang, Methode und Ziel der Musikwissenschaft"

15. Aristides Quintilianus's scheme of music, On Music (c. 3 rd century?)

16. Pratt's ideal scheme of musicology (1915)

17. Seeger's conspectus of musicology, "Systematic Musicology ..." (1951)

18. Sources of musical value, "Sources of Evidence ..."

19. Alternate model of sources of musical judgment, "Sources of Evidence ..."

20. Musicological juncture: five possible relations among speech (S), music (M), individual (I), human culture (C), and physical universe $(\mathrm{P})$

21. Different configuration among speech, music, individual, human culture, and physical universe

\section{Musical Examples}

1. Illustrations of the relative nature of dissonance at (a) and (c); and of consonance at (b) and (d)

2. Illustrations of tripartite models of consonance and dissonance

3. Ruth Crawford, Diaphonic Suite no. 3: II, pitch summary of mm. 34-43

4. Ruth Crawford, String Quartet: III, mm. $39-5^{8}$

5. Major and minor modes, Tradition and Experiment in the New Music

6. (a, b) Chord generation using a mixture of "inferior" and "superior" resonance; (c) example of new "pentad" in Schoenberg, Five Pieces for Orchestra, op. 16: III; (d) example of new "pentad" in Ruggles, Angels

7. Johannes Brahms, Symphony no. 2: I: (a) Piano reduction of mm. 1-6; bass's ternary neume, mm. 1-2, inverted in treble, mm. 2-3 (both marked in brackets); (b) phrase-neume of horn part, mm. 2-5

8. Illustrations of four "conversions" and five other phrase-building operations using excerpts of Ruth Crawford's Diaphonic Suite no. 1: I and II 
9. Illustrations of two tonal "modifications": (a) by octave complement; (b) by fixed interval: perfect fourth

10. Illustrations of various types of modification in Schubert's Symphony in C Major: I

161

11. "Continuity" modification: opening theme from Schubert's Symphony in C modified in six stages into theme from Strauss's 'Till Eulenspiegels lustige Streiche 162

12. Ruth Crawford, Diaphonic Suite no. 1: I, pitch summary 163

13. Ruth Crawford, Diaphonic Suite no. 1: I: (a) mm. 1-3; (b) phrase-neume of mm. 1-3; (c) development of same phrase-neume in $\mathrm{mm} .37-44$ 
